\title{
AVALIAÇÃO DO EFEITO DA COMPOSIÇÃO DO MEIO DA FERMENTAÇÃO EM ESTADO SÓLIDO NA PRODUÇÃO DE ETANOL
}

\author{
H. C. OYAMA ${ }^{1}$, U. C. FILHO ${ }^{1}$, C. M. M. MIRANDA ${ }^{1}$ e V. S. LOPES ${ }^{1}$ \\ ${ }^{1}$ Universidade Federal de Uberlândia, Faculdade de Engenharia Química \\ E-mail para contato: henriquecarlos.oyama@gmail.com
}

\begin{abstract}
RESUMO - A motivação para as pesquisas na área do etanol de primeira e segunda geração se deve, em grande medida, a uma responsabilidade compartilhada e diferenciada do meio ambiente. Nesse panorama científico, este trabalho avaliou o uso de sete extratos enzimáticos (E1 a E7) obtidos a partir de três meios (M1, M2 e M3) da fermentação em estado sólido na produção de etanol de bagaço de cana explodido. Cotejou-se a produção de etanol pelos extratos enzimáticos E1 a E7 para tempos de 24 h e 48 h de fermentação de $250 \mathrm{~g} / \mathrm{L}$ de bagaço de cana explodido, sendo observado que a utilização de diferentes combinações de meios de FES na geração de extratos enzimáticos representa uma estratégia salutar para auferir menores tempos e maiores concentrações de etanol de segunda geração. Os melhores resultados obtidos nesses ensaios foram 21.5 $\mathrm{g} / \mathrm{L}$ de etanol após $24 \mathrm{~h}$ de fermentação.
\end{abstract}

\section{INTRODUÇÃO}

Segundo Trigueiro et al. (2008) construímos um modelo de mundo civilizatório depredador e consumista que, caso seja universalizado, seria necessário três planetas semelhantes ao nosso. Neste milênio, o etanol consagra-se como alternativa para minorar, sobretudo, a problemática ambiental e energética mundial, adensadas pela nociva poluição, escassez e alta dos preços de combustíveis fósseis.

$\mathrm{O}$ alto custo das enzimas celulases (um dos grandes entraves para a consolidação do etanol de segunda geração) torna a fermentação em estado sólido (FES) uma alternativa promissora para a produção enzimática, sendo o bagaço da cana-de-açúcar o principal substrato microbiano utilizado nessa técnica. Na FES o micro-organismo cresce sobre substratos sólidos na ausência livre de água para a produção de extratos enzimáticos (Lopes, 2013).

No cenário atual, a precípua e a potencial aplicação do complexo enzimático obtido da FES é na hidrólise da biomassa lignocelulósica. Desta forma, a premente e fundamental pesquisa científica/tecnológica nos âmbitos acadêmico e industrial devem ser os pilares para a viabilidade econômica e técnica da produção do etanol de segunda geração (Zúñiga, 2010).

Nessa incessante busca por novas rotas alternativas, o presente trabalho avaliou extratos enzimáticos de três diferentes meios de FES e de suas combinações selecionadas na produção de etanol. 


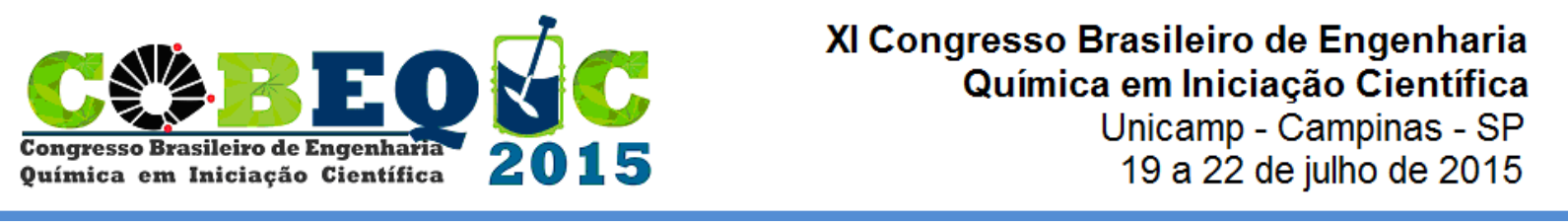

\section{MATERIAIS E MÉTODOS}

\subsection{Micro-organismos}

O extrato enzimático bruto foi obtido a partir do fungo Aspergillus niger, conservado em placas de petri no meio Czapek (Lopes, 2013) contendo ágar e na condição de refrigeração necessária; o cultivo foi renovado a cada 20 dias. Na etapa de produção de etanol empregouse a levedura liofilizada Saccharomyces cerevisiae.

\subsection{Fermentação em estado sólido}

$\mathrm{Na}$ etapa da produção de extrato enzimático bruto foram efetuadas fermentações em estado sólido (FES) durante $72 \mathrm{~h}$ em erlenmeyers de $500 \mathrm{~mL}$ de volume, contendo $10^{8}$ células/g de Aspergillus niger e $40 \mathrm{~g}$ de meio sólido de diferentes composições, conforme apresentado na Tabela 1.

Tabela 1 - Composição dos meios sólidos na FES

\begin{tabular}{|c|l|}
\hline Meio & \multicolumn{1}{|c|}{ Composição } \\
\hline M1 & $\begin{array}{l}\text { 40\% de bagaço de cana tratado com explosão a vapor e 60\% de farelo de arroz } \\
\text { (meio não tamponado }-\mathrm{pH}=6.0 \text { ) }\end{array}$ \\
\hline $\mathrm{M} 2$ & $\begin{array}{l}\text { 40\% de sabugo de milho e } 60 \% \text { de farelo de arroz } \\
\text { (meio não tamponado }-\mathrm{pH}=6.0 \text { ) }\end{array}$ \\
\hline M3 & $\begin{array}{l}\text { 40\% de bagaço de cana tratado com explosão a vapor e } 60 \% \text { de farelo de arroz } \\
\text { em tampão fosfato } \mathrm{pH}=6.0\end{array}$ \\
\hline
\end{tabular}

\subsection{Avaliação do efeito da composição do meio de FES na produção de etanol}

Foi avaliada a produção de etanol após o tempo de $24 \mathrm{~h}$ e $48 \mathrm{~h}$ de fermentação de bagaço de cana explodido na concentração de $250 \mathrm{~g} / \mathrm{L}$, previamente hidrolisado durante $18 \mathrm{~h}$ e $40^{\circ} \mathrm{C}$ por extrato enzimático bruto obtido dos meios M1, M2 e M3 através de extração com tween $801 \%$ na proporção de $100 \mathrm{~mL}$ para cada $40 \mathrm{~g}$ de bagaço.

\subsection{Avaliação dos efeitos da concentração enzimática e proporção dos extratos enzimáticos na produção de etanol}

Investigou-se o efeito da quantidade de enzima disponível no extrato enzimático bruto e da combinação das propriedades dos extratos enzimáticos provenientes dos meios M1, M2 e M3, descritos anteriormente, pela extração de enzima a partir de meios sólidos, como mostrado na Figura 1, e nas combinações especificadas da Tabela 2 com volume final do extrato enzimático bruto de $100 \mathrm{~mL}$ por adição de água destilada. 
Tabela 2 - Extratos das combinações de meios sólidos de FES

\begin{tabular}{|c|c|c|c|}
\hline Extratos & Quantidade de meio & $\begin{array}{c}\text { Meios sólidos } \\
\text { fermentados utilizados }\end{array}$ & $\begin{array}{c}\text { Código para o método de } \\
\text { extração de enzima }\end{array}$ \\
\hline E1 & um meio & M1 & FES 1 \\
\hline E2 & um meio & M2 & FES 1 \\
\hline E3 & um meio & M3 & FES 1 \\
\hline E4 & dois meios & M1 e M2 & FES 1 e FES 2 \\
\hline E5 & dois meios & M1 e M3 & FES 1 e FES 2 \\
\hline E6 & dois meios & M1 e M1 & FES 1 e FES 2 \\
\hline E7 & três meios & M1, M2 e M3 & FES 1, FES 2 e FES 3 \\
\hline
\end{tabular}

Figura 1 - Método de extração de enzima utilizando as combinações de meios sólidos.
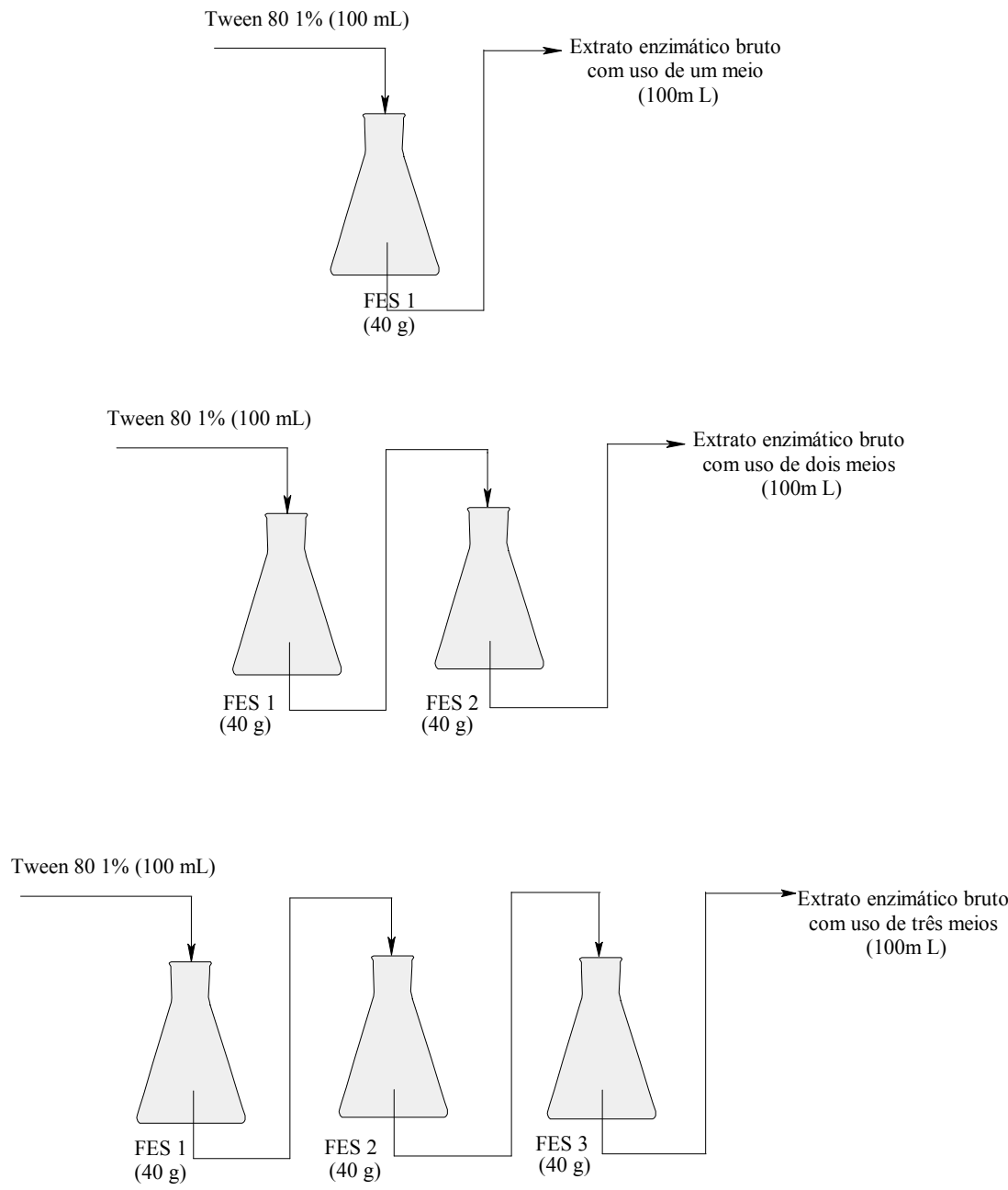

\section{RESULTADOS E DISCUSSÕES}

$\mathrm{Na}$ Figura 2 são apresentados os valores da concentração de etanol obtidos na fermentação com uso do extrato enzimático bruto dos meios M1, M2 e M3. 
Figura 2 - Gráfico da concentração de etanol empregando apenas um meio sólido.

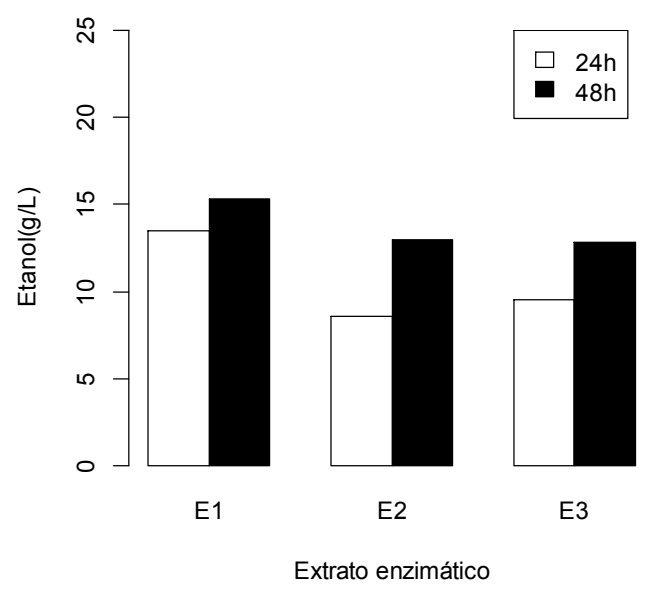

Verifica-se que apesar do sabugo de milho ser rico em celulose e hemicelulose, a escolha deste substrato apresentou reduzida concentração de etanol $(8.6 \mathrm{~g} / \mathrm{L} \mathrm{e} 13.0$ $\mathrm{g} / \mathrm{L}$ em 24 h e 48 h, respectivamente, na etapa de fermentação) em relação aos outros dois meios contendo bagaço de cana tratado com explosão a vapor. Ressalta-se que o enriquecimento dos substratos para a indução das enzimas de interesse (celulases e hemicelulases) foi realizado nas mesmas proporções em todos os três meios.

Infere-se, portanto, que a utilização de um meio profícuo ao desenvolvimento do micro-organismo (M2) pode não favorecer a plena formação do complexo enzimático com as enzimas necessárias para degradação lignocelulósica (Lopes, 2013).

Na condição de M1, observa-se a máxima concentração de etanol obtida entre os ensaios com uso de meios individuais, resultado que confere o bagaço de cana como substrato vantajoso ao país, uma vez que sua disponibilidade é ampla. Além disso, o controle inicial de $\mathrm{pH}=6.0$ de $\mathrm{M} 3$ não apresentou valor satisfatório na produção de etanol.

Na Figura 3 são apresentadas as concentrações de etanol produzido nas combinações de extratos enzimáticos oriundos de M1, M2 e M3, com cada um dos meios individuais contendo os mesmos teores enzimáticos que no teste anterior. 
Figura 3 - Gráfico da concentração de etanol empregando as diferentes combinações de meios sólidos.

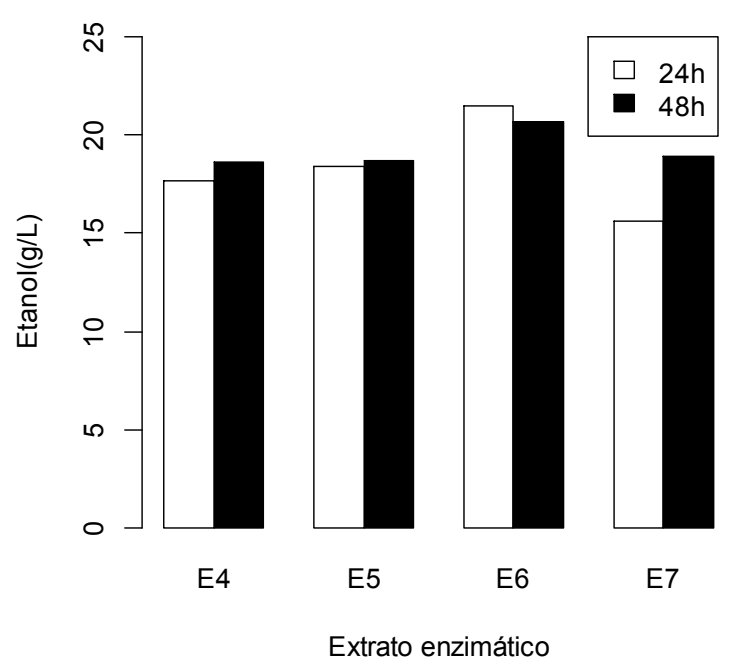

Os resultados obtidos indicam que formas distintas de combinação de extratos enzimáticos de diferentes características influenciam no tempo e concentração de etanol. Coadunar os meios sólidos de FES reduziu o tempo para a produção de determinado teor de etanol em razão da maior quantidade de extrato enzimático utilizado na etapa de fermentação. Os valores quase incólumes de concentração de etanol do quinto ensaio (E5) sugere um equilíbrio nas condições de produção do álcool.

O E6 foi o ensaio com extrato enzimático que ensejou as maiores concentrações de etanol: $21.5 \mathrm{~g} / \mathrm{L}$ e $20.7 \mathrm{~g} / \mathrm{L}$ nos tempos de $24 \mathrm{~h}$ e $48 \mathrm{~h}$, respectivamente. Porém, como foi empregado teor de extrato enzimático equivalente em dois meios sólidos M1, esperava-se obter uma maior influência do extrato enzimático na concentração de etanol em relação ao uso de somente um M1 (13.5 g/L em $24 \mathrm{~h}$ e $15.3 \mathrm{~g} / \mathrm{L} \mathrm{em} 48 \mathrm{~h}$, aferido da Figura 2). Ademais, observa-se uma redução de $3.7 \%$ na concentração do produto no tempo de $48 \mathrm{~h}$ em E6, indicando que já neste tempo se estabelece condições deletérias às leveduras.

O uso do extrato enzimático E7 apresentou redução de $27.4 \%$ na produção de etanol comparado ao melhor ensaio com extrato enzimático proveniente de dois meios (E6) no tempo de $24 \mathrm{~h}$, sendo que em 48 h obteve-se uma concentração semelhante aos ensaios de E1 e E2, os quais foram avaliados utilizando apenas dois meios sólidos.

\section{CONCLUSÃO}

A análise dos diferentes meios e ensaios mostrou que a escolha do meio sólido na FES é um fator tão importante e essencial quanto à seleção do micro-organismo nesta etapa.

A ação sinérgica e complementar do extrato enzimático total combinado favoreceu a produção de determinado teor de etanol em menor espaço de tempo, em virtude da quantidade 


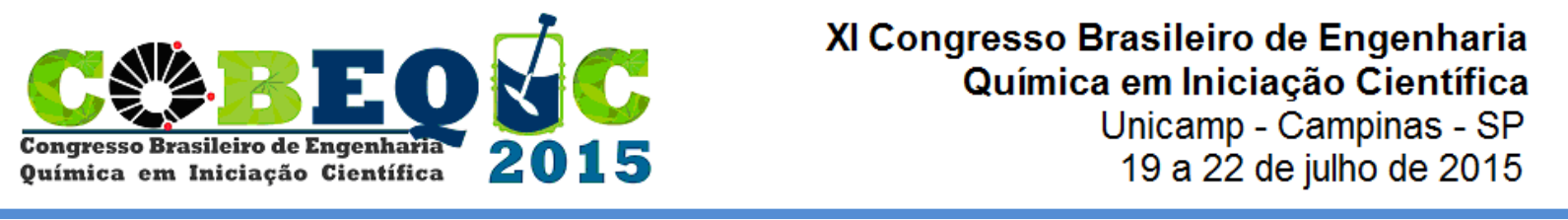

e das características das enzimas presentes. O melhor resultado obtido foi o ensaio com E6 que atingiu a concentração de $21.5 \mathrm{~g} / \mathrm{L}$ de etanol em 24 h de fermentação.

Dessa forma, o ponto fulcral do aperfeiçoamento e fomento da produção de etanol é a pesquisa de novas maneiras e técnicas de aumento da concentração do produto avaliado em um intervalo de tempo desejado. Para dirimir um dos grandes gargalos do quadro mundial da viabilidade econômica do etanol de segunda geração, é fundamental a avaliação de diferentes meios sólidos de FES e suas combinações possíveis, levando em consideração aspectos quantitativos e qualitativos do complexo enzimático obtido.

\section{REFERÊNCIAS}

LOPES. V. S. Avaliação de complexos enzimáticos obtidos a partir de fungos do Cerrado para produção de etanol de segunda geração. 2013. 61f. Dissertação (Mestrado em Engenharia Química) - Faculdade de Engenharia Química, Universidade Federal de Uberlândia, MG.

TRIGUEIRO, A. et al. Meio ambiente no século 21: 21 especialistas falam da questão ambiental nas suas áreas de conhecimento. 5ed. Campinas-SP: Armazém do IP (Autores associados), 2008.

ZÚÑIGA, U. F. R. Desenvolvimento de um bioprocesso para produção de celulases específicas na cadeia produtiva do etanol de segunda geração. 2010. 228 f. Tese (Doutorado em Ciências da Engenharia Química) - Escola de Engenharia de São Carlos, São Carlos, SP.

\section{AGRADECIMENTOS}

Aos autores agradecem a Universidade Federal de Uberlândia, a Faculdade de Engenharia Química e o Programa de Educação Tutorial por possibilitarem a realização deste trabalho. 